\title{
LA CRISIS DEL ALUMBRADO DE GAS EN LAS CIUDADES ESPAÑOLAS DURANTE LA I GUERRA MUNDIAL
}

\section{THE CRISIS OF GASLIGHTING IN SPAIN CITIES DURING WORLD WAR I}

\author{
Mercedes Fernández-Paradas* \\ Universidad de Málaga, España
}

\begin{abstract}
RESUMEN: Este artículo analiza las consecuencias de la I Guerra Mundial sobre la actividad gasista, en especial el alumbrado de gas, periodo en el que experimentó una aguda crisis, cuya dimensión examinamos. Para ello, analizamos la evolución de la producción de gas, las empresas, el número de fábricas, el número de municipios con iluminación por gas y los ingresos por venta de gas, en especial de los ayuntamientos. Asimismo, estudiamos los problemas a los que se enfrentó la industria del gas, principalmente la falta de carbón y la subida de costes. También las estrategias implementadas por las empresas de gas para hacer frente al incremento de los costes, la protesta obrera, la competencia de la electricidad y la decisión del Gobierno central de reducir a la mitad el alumbrado público generado con carbón. Así como las medidas que éste tomó para evitar el desabastecimiento de carbón, y de las corporaciones municipales, que pretendían que sus calles continuasen iluminadas.
\end{abstract}

PALABRAS CLAVE: ciudad, ayuntamiento, servicios públicos, alumbrado de gas, industria, I Guerra Mundial.

ABSTRACT: This paper analyzes the consequences of the First World War on gas activity, especially gas lighting, a period in which it experienced a severe crisis, whose dimension is examined. In order to do this, several aspects must be considered: the evolution of gas production, companies, the number of factories, the number of municipalities with gas lighting and the incomes obtained from gas sales, especially from town halls. At the same time, the problems faced by the gas industry, mainly the lack of coal and the rising costs, are studied. Not only will be discussed the strategies implemented by the gas companies to face this increase, but also the workers' protests, the competition of electricity and the decision of the central government to halve the public lighting generated with coal. Besides, the way some local and national policies had to be implemented by applying several guidelines to avoid the shortage of coal, in the interest of keeping their towns supplied with illumination.

KEYWORDS: city, city hall, public services, gas lighting, industry, World War I.

* Correspondencia a: Mercedes Fernández-Paradas. Universidad de Málaga. Facultad de Filosofía y Letras. Departamento de Historia Moderna y Contemporánea. Campus Universitario de Teatinos, s/n. Málaga 29071 - paradas@uma.es https://orcid.org/0000-0002-3049-0907

Cómo citar: Fernández-Paradas, Mercedes (2019). «La crisis del alumbrado de gas en las ciudades españolas durante la I Guerra Mundial»; Historia Contemporánea, 59, 127-159. (https://doi.org/10.1387/hc.18764).

Recibido: 19 noviembre, 2017; aceptado: 3 mayo, 2018.

ISSN 1130-2402 - eISSN 2340-0277 / (C) 2019 UPV/EHU

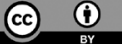

Esta obra está bajo una licencia

Creative Commons Atribución 4.0 Internacional 


\section{Introducción}

La I Guerra Mundial tuvo efectos positivos y negativos sobre la economía y la sociedad española. Como es sabido, España fue neutral. A nivel económico, hubo sectores que obtuvieron pingües beneficios al aprovecharse de la menor competencia internacional y de la demanda exterior, al aprovechar las oportunidades planteadas por el conflicto, derivadas de la necesidad de dar respuesta a la demanda de los contendientes, así como de proveer a aquellos países cuyos suministradores tradicionales estaban inmersos en la conflagración ${ }^{1}$. La industria del gas estuvo entre las actividades económicas seriamente perjudicadas por la desarticulación del comercio internacional, al quedar desabastecida de materias primas, principalmente carbón. A nivel social, si bien nuestra economía generó empleo, el conflicto también provocó una subida de precios superior al de los salarios. De ahí la presión de los trabajadores para mejorar sus condiciones laborales, problemática que también afectó a las empresas de gas².

En este estudio analizamos las consecuencias de la Gran Guerra sobre la actividad gasista, en especial el alumbrado de gas, años en los que sufrió una aguda crisis, cuya dimensión pretendemos examinar en esta investigación. Para ello, estudiamos la evolución de la producción, las empresas, el número de fábricas, el número de municipios con alumbrado de gas y los ingresos por venta de gas, en especial los procedentes de los ayuntamientos, de estos casi la totalidad del consumo de gas se destinaba a iluminación. También examinamos los problemas a los que se enfrentó la industria gasista, principalmente la falta de carbón y la subida de costes. Así como las estrategias implementadas por las compañías de gas para enfrentarse al alza de los gastos, la protesta obrera, la competencia de la electricidad y la decisión del gobierno de reducir a la mitad el alumbrado público generado con carbón. Así como las medidas del Gobierno central para evitar el desabastecimiento de carbón, y de los consistorios, que querían que sus calles continuasen iluminadas. Cabe reseñar que este es el primer estudio específico sobre el alumbrado de gas en España en la Gran Guerra ${ }^{3}$. Este trabajo se fundamenta en fuentes primarias y secunda-

${ }^{1}$ Comín, 2002, pp. 287-289. Carreras y Tafunell, 2003, pp. 223-224.

2 Comín, 2002, p. 289. Carreras y Tafunell, pp. 225 y 230-231.

${ }^{3}$ Como se comprobará en este texto, este asunto apenas ha sido abordado por los investigadores, al respecto cabe reseñar las aportaciones sobre Galicia, Córdoba y Cádiz. A. Martínez (coord.), Mirás y Lindoso, 2009, pp. 212-216. Fernández-Paradas, 2009a, pp. 94-101, y 2015a, pp. 157-160. 
rias, entre ellas, cabe reseñar la Estadística del Impuesto sobre el consumo de luz de gas, electricidad y carburo de calcio ${ }^{4}$, el Anuario Financiero y de Sociedades Anónimas ${ }^{5}$, la Gaceta de Madrid y de Catalana de Gas y Electricidad, la principal empresa en aquellos años, las Actas de las Juntas Generales de Catalana, las Actas del Consejo de Administración y las Explicaciones dadas por el Consejo de Administración en la Junta General de Accionistas.

\section{La crisis de la industria del gas}

Veamos algunos datos que muestran la profundidad de la crisis que sufrió la industria del gas y su diferente alcance a nivel empresarial y territorial (Cuadros 1-4). En el siguiente epígrafe nos centraremos en el alumbrado de gas. El Cuadro 1 informa acerca de la evolución del sector a lo largo del periodo considerado y en el año 1913, con la finalidad de poder valorar el impacto del declive de la actividad gasista en relación a la situación existente antes del inicio de la conflagración.

En cuanto a la producción de gas, los datos de 1913 a 1915 están infravalorados porque la Estadística del Impuesto sobre el consumo de luz no incluye las cifras de producción de varias provincias ${ }^{6}$. Los de 1916-1918 son fiables ya que consideran toda la fabricación. En 1916 superó los 71,8 millones de $\mathrm{m}^{3}$, cifra que en 1917 se redujo a los 48,9 millones de $\mathrm{m}^{3}$, es decir, fue un 32\% menor. En 1918 sumó más de 56 millones de $\mathrm{m}^{3}$, una cifra bastante mayor que la de 1917, si bien todavía fue un $22 \%$ inferior a la de 1916. Es decir, entre 1916 y 1918,

${ }^{4}$ Dirección General de Propiedades e Impuestos, Estadística del Impuesto sobre el consumo de luz de gas, electricidad y carburo de calcio, Editada por Imprenta de la Sucesora de M. Minuesa de los Ríos para los años 1913-1916, Editada por la Imprenta Sobrinos de la Sucesora de M. Minuesa de los Ríos para 1917-1918, Editada por la Imprenta de la Fábrica Nacional de Moneda y Timbre para 1919-1921. Sobre las carencias de esta fuente, véase Martínez López y Mirás Araujo, 2018, p. 89. Estos autores señalan que su «carácter fiscal plantea el consabido problema de la fiabilidad de este tipo de fuente» y que en «la propia estadística se reconocen carencias o infravaloraciones concretas, como el hecho de no recoger la producción durante varios años de algunas empresas que estaban sujetas a contribución de utilidades».

${ }^{5}$ Riu Yferiquet (dir.), 1920.

6 Tampoco comprende los del País Vasco y Navarra con un régimen tributario diferente. Sobre esta fuente, véase Fernández-Paradas, 2007. Por entonces, de estas regiones, sólo el País Vasco contaba con dos fábricas de gas. 
1917 fue el peor año, y en 1918 hubo una cierta recuperación, insuficiente para retomar los niveles de 1916. Si bien no disponemos de datos fiables de generación de gas para 1913-1915, es muy posible que apenas experimentase reducciones en estos años, así lo indicarían el resto de variables del Cuadro 1 . Como veremos más adelante, la producción de gas de Catalana de Gas y Electricidad en esos años reforzaría esta idea (Cuadro 4).

\section{Cuadro 1}

La industria gasista en España (1913-1918).

Producción y número de empresas y de fábricas. $1913=100 *$

\begin{tabular}{c|cc|cr|rr}
\hline Años & \multicolumn{2}{|c|}{ Producción gas $\left(\mathrm{m}^{3}\right)$} & \multicolumn{2}{|c|}{ N.o empresas } & \multicolumn{2}{c}{ N.o fábricas } \\
\hline 1913 & $21.854 .144,71$ & 43 & 100 & 70 & 100 \\
1914 & $16.398 .266,68$ & & 44 & 102 & 70 & 100 \\
1915 & $18.603 .149,00$ & & 41 & 95 & 67 & 95 \\
1916 & $71.864 .293,00$ & 100 & 41 & 95 & 66 & 94 \\
1917 & $48.975 .208,00$ & 680 & 41 & 95 & 65 & 95 \\
1918 & $56.094 .545,52$ & 780 & 37 & 86 & 52 & 74 \\
\hline
\end{tabular}

* Excepto los datos de producción de gas.

Fuente: Dirección General de Propiedades e Impuestos, años 1913-1918. Elaboración propia.

La fabricación de gas en España se comportó peor que la de Gran Bretaña, pese a que este fue uno de los principales contendientes, lo que confirma la intensidad de la crisis en nuestro país. En 1913 la industria gasista británica generó 5.960 millones de $\mathrm{m}^{3}$, durante toda la guerra superó esa cifra. Es más, respecto de ese año, en 1914 aumentó del orden del 5\%, otro porcentaje similar en 1915, manteniéndose los niveles de producción en 1916-1918 en torno a los 6.600 millones de $\mathrm{m}^{37}$.

El Cuadro 2 muestra el reparto de la fabricación de gas por regiones, entre 1916 y 1918 en términos porcentuales. En 1916 estaba muy desigualmente repartida, concentrándose casi el $75 \%$ en Cataluña (el $47,77 \%)$, Andalucía $(15,04 \%)$ y Madrid $(12,08)$. Del resto de los territo-

\footnotetext{
7 The Gas World Year Book, Años 1913-1919.
} 
rios con gas, solo Valencia ${ }^{8}$ y Baleares reunían más del $5 \%$ respectivamente. En los dos años siguientes la tendencia fue a una mayor concentración de la producción. En 1918, Cataluña sumó el 72,8\%, debido a un incremento espectacular de la fabricación de ese año, que fue muy superior a las de 1916-1917. Entre 1916 y 1918 solo en Cataluña y Murcia creció la producción. El «peso» de esta última era muy pequeño en el sector. En definitiva, Cataluña habría sido la única región que en 1918 había logrado superar con creces el nivel de fabricación de 1916. Por el contrario, en Andalucía y Madrid la producción decreció de manera importante, del orden del $50 \%$ en el primero caso y del $70 \%$ en el segundo. Canarias dejó de generar gas.

\section{Cuadro 2}

El reparto de la producción de gas en España por regiones en \% (1916-1918)

\begin{tabular}{|c|c|c|c|}
\hline Regiones/Años & 1916 & 1917 & 1918 \\
\hline Andalucía & 15,04 & 15,51 & 9,00 \\
\hline Aragón & 0,83 & 8,10 & 0,28 \\
\hline Asturias & 2,74 & 2,97 & 0,26 \\
\hline Baleares & 5,75 & 8,08 & 3,78 \\
\hline Canarias & 0,04 & 0,03 & \\
\hline Cantabria & 2,94 & 3,70 & 1,86 \\
\hline Cataluña & 47,77 & 45,50 & 72,80 \\
\hline Castilla León & 2,94 & 3,70 & 1,86 \\
\hline Castilla La Mancha & 0,12 & 0,15 & 0,12 \\
\hline Galicia & 2,90 & 1,43 & 0,40 \\
\hline La Rioja & 0,02 & 0,02 & 0,03 \\
\hline Madrid & 12,08 & 3,64 & 5,36 \\
\hline Murcia & 0,02 & 0,02 & 0,03 \\
\hline Valencia & 6,92 & 7,03 & 3,00 \\
\hline Total & 100,00 & 100,00 & 100,00 \\
\hline
\end{tabular}

Fuente: Dirección General de Propiedades e Impuestos. Años 1916-1918. Elaboración propia.

${ }^{8}$ Cuando nos referimos a Valencia se corresponde con la actual comunidad de Valencia, en este trabajo utilizamos el término región como equivalente a las actuales comunidades autónomas. 
En lo relativo a las empresas de gas, en 1913 había 43, cifra que aumentó ligeramente en 1914, en 1915-1917 disminuyó hasta 41, mayor fue la merma de 1918, en ese año hubo 37, un $14 \%$ menos que en 1913. Todas suministraban luz de gas. En el número de gasistas no están incluidas La Propagadora del Gas y La Energía porque eran filiales de Catalana de Gas y Electricidad. La mayoría eran pequeñas empresas, solían abastecer a un municipio y a mercados de reducido tamaño.

Casi todas las compañías de gas que dejaron de tener actividad entre 1914 y 1918 eran de pequeñas dimensiones: Alcoyana de Gas, Benito González Suazo (Ciudad Real), El Gas (Lluch Mayor, Baleares), Gasómetro Arbonense (Arbós, Tarragona), Gasómetro Tarraconense y Gaswerk Santa Cruz de Tenerife ${ }^{9}$. A este listado hay que sumar dos de mayor relevancia, la Société Anonyme des Villes de Corogne et Vigo y The Huelva Gas and Electricity, a las que nos referiremos más adelante.

Según la nacionalidad de las empresas, en 1913 la producción de gas se repartió como sigue: el 50,07\%, las foráneas; el 49,3\% las españolas. En 1918: el $12,26 \%$ y el $87,74 \%$ respectivamente. Por tanto, constamos un cambio significativo. De estas cifras se deriva la necesidad de analizarlas por separado, según fuesen españolas o no. Empezaremos por las de capital nacional. En 1913 había 31, es decir, el 72,09\% del total. En 1918 eran 31, el 83,78\% del total. Por tanto, avanzaron en detrimento de las extranjeras. Si bien en 1913 y 1918 coincide el número de compañías españolas, hubo cambios ya que, como hemos explicado, desaparecieron pequeñas empresas que fueron reemplazadas.

Catalana de Gas y Electricidad era la gasista de capital español más importante. En 1912 la Sociedad Catalana de Alumbrado por Gas, constituida en 1843 para suministrar gas a Barcelona, adquirió a la Compañía Lebon el 50\% de la Central Catalana de Electricidad, sociedad que habían fundado en 1896, es decir, se hizo con la totalidad de la empresa. En 1912 la Sociedad Catalana de Gas creó la Sociedad General de Fuerzas Hidro-Eléctricas (SGFH), a la que aportó el 38\% del capital. A finales de ese año pasó a denominarse Catalana de Gas y Electricidad ${ }^{10}$. En 1913 compró La Energía de Sabadell y La Propagadora del Gas, con fá-

9 En los casos de las gasistas de Alcoy, Lluch Mayor, Arbós y Taragona supuso el fin del alumbrado de gas. En Ciudad Real el negocio pasó a Francisco González del Valle y en Santa Cruz de Tenerife la actividad fue retomada por Gaswerk en 1920. García de la Fuente, 2007, p. 145. Dirección General de Propiedades e Impuestos, Años 1913-1920.

10 Arroyo, 1996. Fàbregas, 2014. 
bricas de gas en Badalona, Premià del Mar y Tarrasa ${ }^{11}$. En 1913 surtía de gas a 6 poblaciones, casi todas ellas en Cataluña, concretamente en la provincia de Barcelona, con la excepción de Sevilla. El Cuadro 3 refleja la trayectoria de la generación de gas de Catalana de Gas y Electricidad en Barcelona. En 1914 produjo un 6\% más de gas que en 1913, en 1915 aumentó ligeramente, en 1916-1918 experimentó un retroceso continuado hasta situarse en 1918 en los 17,17 millones de $\mathrm{m}^{3}$, dos tercios de la fabricación de 1913. Esta última cifra sumó en torno a un tercio de la producción nacional en 1918. De ahí la relevancia de esta empresa y del mercado barcelonés.

\section{Cuadro 3}

Producción de gas de Catalana de Gas y Electricidad en Barcelona (1913-1918)

\begin{tabular}{ccc}
\hline Años & Producción $\left(\mathrm{m}^{3}\right)$ & $1913=100$ \\
\hline 1913 & 28.500 .000 & 100 \\
1914 & 30.100 .000 & 106 \\
1915 & 30.400 .000 & 107 \\
1916 & 25.600 .000 & 90 \\
1917 & 22.200 .000 & 78 \\
1918 & 17.700 .000 & 62 \\
\hline
\end{tabular}

Fuente: Arroyo, 1996, p. 358.

El resto de las empresas españolas se situaban muy lejos de Catalana de Gas y Electricidad. La mayoría no solían producir más de $100.000 \mathrm{~m}^{3}$ al año. En 1918, además de Catalana de Gas, otras 6 fabricaron más de $500.000 \mathrm{~m}^{3}$ (Unión Industrial en Villanueva y la Geltrú y Castellón, Gas de Córdoba, Gas Reusense, La Económica y la Sociedad de Alumbrado por Gas en Palma de Mallorca).

\footnotetext{
11 Arroyo, 1996, p. 365. Dirección General de Propiedades e Impuestos, Ejercicio 1919-1920.
} 
En lo que se refiere a las compañías foráneas ${ }^{12}$, hemos explicado que antes del inicio de la I Guerra Mundial eran muy relevantes en el conjunto del sector. De las 44 empresas de gas que vendían luz de gas en 1913, 8 eran extranjeras, es decir, el 18,60\% del total. En 1918 eran 5, el 13,51\%. Un repliegue en su actividad que también se manifestó en la disminución del gas que generaban respecto de la producción total, el cual en 1913 representó el 50,07\%, en 1918 solo el 12,26\%. La mayor parte de este retroceso se debió a la caída de la fabricación de la Compañía Lebon y de la Compañía Madrileña, ambas sumaban en 1913 casi el 39\% de la producción del país, en 1918 solo el 7,9\%.

En 1913, en España las gasistas foráneas eran: Compañía Lebon, Societé pour l'Éclairage des villes de Biarritz et Saragosse ${ }^{13}$, Compañía Madrileña de Alumbrado y Calefacción por Gas, Société Civile pour l'Éclairage de Málaga ${ }^{14}$, Gaswerk Santa Cruz de Tenerife ${ }^{15}$, Roberto Lassage ${ }^{16}$ y Société Anonyme des Villes de Corogne et Vigo ${ }^{17}$. Según el origen de su capital, había: 5 francesas (Lebon et Cie, Compañía Madrileña, Corogne et Vigo, Société Civile pour l'Éclairage de Málaga y Societé pour l'Éclairage des villes de Biarritz et Saragosse); 1 alemana (Gaswerk); 1 belga (Robert Lessage); y 1 británica (The Huelva Gas and Electricity).

Las empresas extranjeras más importantes eran la Compañía Lebon y la Compañía Madrileña de Alumbrado y Calefacción por Gas. En 1847, el francés Charles Lebon (1799-1877) constituyó la Compagnie Centrale d'Éclairage par le Gaz, Lebon et Cie. En 1913, en España era propietario de las fábricas de gas y electricidad de Cádiz, San-

12 Sobre las gasistas extranjeras en España, véanse: Costa Campi, 1981, p. 55-57; Broder, 1981; Arroyo, 2002; Martínez, 2014; y Castro Balaguer, 2007, pp. 90, 93-95 y 102.

${ }^{13}$ En 1864 Credit Lyonnais se hizo con la concesión del alumbrado de gas de Zaragoza, el negocio lo traspasó a Mr. Genin en 1870. Sus herederos crearon la Societé pour l'Éclairage des villes de Biarritz et Saragosse. Germán, 1990, p. 18.

${ }^{14}$ Société pour l'Éclairage de Málaga formaba parte del grupo Vautier, el cual a finales del ochocientos tenía factorías de gas en Francia, Alemania, Italia y España. Su fundador, Paul-Émile Vautier (1818-1889), en 1863 participó en la constitución del banco Crédit Lyonnais. Arroyo, 2001.

15 En 1906 esta empresa, controlada por el constructor Carl Francke, comenzó a suministrar gas en Santa Cruz de Tenerife. Matos, 2005, pp. 375-376.

16 Es posible que el capital francés tuviese participación, ya que también aparece con el nombre de Gas Franco-Belge. Robert Lessage et Cie. Fernández-Paradas, 2015a. Sobre esta empresa, véase Bartolomé Rodríguez y Girón Sierra, 2018, pp. 57-87.

17 Fundada en Lyon, en 1906. Mirás, 2007, pp. 73-74. 
tander y Murcia y las de gas de Almería, Granada, Valencia y Puerto de Santa María. Con los datos de que disponemos para $1913^{18}$, en ese año sumó el 26,11\% del gas fabricado en España, porcentaje que cayó al $3,67 \%$ en 1918. En lo que respecta a su actividad a nivel territorial, de todas las gasistas, con independencia de que fuesen españolas o no, en 1913 y durante la I Guerra Mundial fue la que suministró a mayor número de municipios (8), situados en Andalucía, Cantabria, Cataluña, Murcia y Valencia.

La Compañía Madrileña de Alumbrado y Calefacción por Gas, creada en 1865 para suministrar gas a Madrid, formaba parte del Grupo Pereire, fundado en 1852 por los hermanos Émile e Isaac Pereire en París. En 1868 se hizo con la factoría de gas de Murcia. En 1880 adquirió a la firma holandesa del Grupo Stockman las fábricas de gas de Burgos, Cartagena, Alicante, Pamplona, Valladolid y Jerez. En 1881 levantó una factoría de gas en Logroño ${ }^{19}$. En 1913 continuaba siendo propietaria de todas esas factorías, salvo la de Pamplona, clausurada, y la de Madrid, que había sido incautada por el ayuntamiento en $1917^{20}$. En 1913 la Compañía Madrileña reunió el 12,77\% de la producción total de gas; en 1918, el 4,27\%. Por tanto, había perdido peso en el conjunto del sector. En 1913, por número de municipios a los que abastecía (5), era la segunda empresa foránea más importante, y la tercera respecto del total ${ }^{21}$. En 1918 vendía gas en Andalucía, Logroño, Navarra y Castilla León.

En lo concerniente al número de factorías (Cuadro 1), también experimentaron una disminución importante. En 1913-1914 fueron 70, a partir de 1915 y hasta 1917 se redujeron a razón de una por año, en 1918 hubo 52, 13 menos que el año anterior. Más adelante analizaremos los motivos de su cierre - temporal o definitivo- ${ }^{22}$, principalmente la reducción por el gobierno a la mitad del alumbrado público de gas, la falta de carbón y el incremento de los costes laborales - lo que redundó en una caída de los

\footnotetext{
18 Recuérdese que las cifras de producción de ese año están infravaloradas.

19 A comienzos del siglo XX, el grupo Pereire tenía fábricas de gas en Francia e Italia. Arroyo, 2002. Fàbregas, 2003, pp. 90-94. Martínez López, 2014.

20 De nuevo la factoría de gas de Madrid pasó a manos privadas en 1922, en concreto a Gas Madrid controlada por eléctricas españolas, la Compañía Madrileña era socio minoritario. Simón Palmer, 1989, pp. 123-125.

${ }^{21}$ Le seguía Mutua Industrial con dos fábricas, una en Cataluña, la otra en Valencia. Dirección General de Propiedades e Impuestos, Años 1913-1918.

22 En 1919 funcionaron 58 factorías de gas. Fernández-Paradas y Larrinaga, 2018.
} 
beneficios que colocaron a las empresas de gas en una situación complicada - y la competencia del sector eléctrico.

Respecto de la salida de las gasistas extranjeras de España, en diciembre de 1917 The Huelva Gas and Electricity dejó de suministrar gas definitivamente, vendió sus instalaciones a Antonio de Mora en 1919, ese mismo año tuvo lugar su liquidación ${ }^{23}$. El 1 de noviembre de 1918 la Société Anonyme des Villes de Corogne et Vigo fue adquirida por capital gallego (Cuadro 4). La Cooperativa Eléctrica Coruña S.A. - creada en 1906 - constituyó la filial Fábricas Coruñesas de Gas y Electricidad. Pocos días después, esta última y Electra Popular de Vigo y Rendondela adquirieron los activos de la extinguida Société d'Eclairage et Chaufage et de Force Motrice de Corogne et Vigo. Detrás de esta operación estaba Sobrinos de José Pastor y Cía, del futuro Banco Pastor, el principal grupo financiero de Galicia ${ }^{24}$. Por tanto, hubo avances en el proceso de españolización de la actividad gasista ${ }^{25}$.

Por regiones, el impacto de la I Guerra Mundial se dejó notar de desigual manera. En 1913 llegaba el gas a Andalucía, Aragón, Asturias, Baleares, Canarias, Cataluña, Castilla León, Castilla La Mancha, Galicia, La Rioja, Madrid, Murcia y Valencia ${ }^{26}$. La mayoría eran costeras. La extensión del gas era mínima ya que solía llegar, como máximo a dos municipios por región. El grueso de la actividad gasista se concentraba, por orden de importancia, en las regiones costeras de Cataluña, con el $40 \%$ de las factorías, Andalucía el 17,14\%, y Baleares y Valencia con el 10\% respectivamente. Es decir, estos cuatro territorios sumaban casi el $78 \%$ de las fábricas. A continuación, examinamos de manera más específica la evolución del alumbrado de gas.

${ }^{23}$ Martínez, 2017, pp. 215-235.

24 Mirás, 2007, pp. 73-74. Martínez (Coord.,) Mirás y Lindoso, 2009, pp. 299 y 304.

25 Proceso que se acentuó en el periodo de entreguerras. Fernández-Paradas y Larrinaga, 2018.

${ }^{26}$ Esta información está elaborada con la Estadística del Impuesto sobre el consumo de luz de gas, electricidad y carburo de calcio. Recuérdese que esta fuente no incluye la fábrica de Bilbao (País Vasco). 


\section{Cuadro 4}

\section{Las empresas gasistas extranjeras en España (1913-1918)}

\begin{tabular}{|c|c|c|c|c|c|c|}
\hline Nombre & Nacionalidad & $\begin{array}{c}\text { Municipios a los } \\
\text { que suministraba } \\
\text { luz de gas en } 1913\end{array}$ & $\begin{array}{c}\text { Municipios a los } \\
\text { que suministraba } \\
\text { luz de gas en } 1918\end{array}$ & $\begin{array}{l}\text { \% respecto de } \\
\text { la producción } \\
\text { total de gas en } \\
1913 \text { y } 1918\end{array}$ & $\begin{array}{l}\text { Año en el } \\
\text { que dejó de } \\
\text { vender luz } \\
\text { de gas }\end{array}$ & $\begin{array}{l}\text { Empresa } \\
\text { compradora }\end{array}$ \\
\hline Lebon \& Cie. & Francesa & $\begin{array}{l}\text { Almería, Barce- } \\
\text { lona, Cádiz, Gra- } \\
\text { nada, Murcia, } \\
\text { Puerto de Santa } \\
\text { María, Valencia } \\
\text { y Santander }\end{array}$ & $\begin{array}{l}\text { Almería, Barce- } \\
\text { lona, Cádiz, Gra- } \\
\text { nada, Murcia, } \\
\text { Puerto de Santa } \\
\text { María, Valencia } \\
\text { y Santander }\end{array}$ & 26,11 & & \\
\hline $\begin{array}{l}\text { Compañía Madrileña } \\
\text { de Alumbrado y Cale- } \\
\text { facción por Gas }\end{array}$ & Francesa & $\begin{array}{l}\text { Burgos, Jerez, } \\
\text { Logroño, } \\
\text { Madrid y Valla- } \\
\text { dolid }\end{array}$ & $\begin{array}{l}\text { Burgos, Jerez, } \\
\text { Logroño y Valla- } \\
\text { dolid }\end{array}$ & 12,77 & & \\
\hline $\begin{array}{l}\text { Gaswerk Santa Cruz de } \\
\text { Tenerife }\end{array}$ & Alemana & $\begin{array}{l}\text { Santa Cruz de } \\
\text { Tenerife }\end{array}$ & & & $1917 *$ & \\
\hline Robert Lessage & Belga & $\begin{array}{l}\text { Sanlúcar de Ba- } \\
\text { rrameda }\end{array}$ & & s.d. & & \\
\hline $\begin{array}{l}\text { Société Anonyme des } \\
\text { Villes de Corogne et } \\
\text { Vigo }\end{array}$ & Francesa & A Coruña y Vigo & & 5,40 & 1918 & $\begin{array}{l}\text { Electra Popular } \\
\text { de Vigo y Re- } \\
\text { dondela/Fábri- } \\
\text { cas Coruñesas } \\
\text { de Gas y Electri- } \\
\text { cidad }\end{array}$ \\
\hline $\begin{array}{l}\text { Société Civile pour } \\
\text { l'Éclairage de Málaga }\end{array}$ & Francesa & Málaga & Málaga & $0,39 \quad 3,99$ & & \\
\hline $\begin{array}{l}\text { Societé pour l'Éclairage } \\
\text { des villes de Biarritz et } \\
\text { Saragosse }\end{array}$ & Francesa & Zaragoza & Zaragoza & $0,12 \quad 0,28$ & & \\
\hline $\begin{array}{l}\text { The Huelva Gas and } \\
\text { Electricity Company }\end{array}$ & Británica & Huelva & Huelva & 4,88 & 1917 & Antonio de Mora \\
\hline $\begin{array}{l}\% \text { respecto de la pro- } \\
\text { ducción total }\end{array}$ & & & & $50,07 \quad 12,26$ & & \\
\hline
\end{tabular}

* Recuérdese que esta empresa retomó su actividad en 1920.

s.d.: sin datos.

Fuente: Archivo Municipal de Sanlúcar de Barrameda (AMSB), Documento sin signatura, Carta de Robert Lessage al Ayuntamiento de Sanlúcar de Barrameda; Dirección General de Propiedades e Impuestos. Años 1913-1918. Martínez López, 2014 y 2017. Elaboración propia. 


\section{La crisis del alumbrado de gas}

Para estudiar el alumbrado de gas nos basaremos fundamentalmente en los datos ofrecidos por la mencionada Estadística del Impuesto sobre el consumo de luz. La Ley de Presupuesto de 28 de junio 1898 contempló la creación de un gravamen sobre el consumo de luz de gas, electricidad y carburo de calcio. Un día después, Joaquín López Puigcerver, a la sazón Ministro de Hacienda, firmó el reglamento que reguló el nuevo impuesto. El artículo 1. ${ }^{\circ}$ estableció la tarifa a aplicar a la industria del gas: el $10 \%$ del valor de venta por cada metro cúbico de gas consumido. De ahí que la estadística sobre dicho tributo recogiese las cantidades ingresadas por las empresas de gas en concepto de suministro de gas, es preciso señalar que en los años aquí estudiados se referían a todo el consumo, no solo al alumbrado. La ley de 24 de diciembre de 1912, con la finalidad de obtener mayores ingresos, aprobó un alza en dicho impuesto, distinguiendo entre ayuntamientos y particulares. Los consistorios continuaron abonando la tarifa vigente hasta entonces - el mencionado $10 \%$ sobre el precio de compra del gas consumido- . Para los particulares, ese porcentaje subió hasta el 17\%. En la Estadística de 1915 se introdujeron estas novedades, lo que nos permite conocer las cantidades ingresadas por las compañías de gas de particulares y corporaciones municipales ${ }^{27}$. Hay que reseñar que por entonces casi todo el consumo de gas de los ayuntamientos era destinado a alumbrado público. Igualmente, que en general estaban poco desarrollados usos diferentes al de alumbrado ${ }^{28}$.

Las cifras recogidas en el Cuadro 5 sobre los ingresos de las gasistas por consumo de gas muestran que la profundidad de la crisis fue mayor de lo indicado en este estudio hasta ahora ${ }^{29}$. El número de localidades que suministraban gas apenas habría retrocedido. ¿A qué se debe esta divergencia? En realidad, adelantamos que no hubo diferente comportamiento. El número de municipios está sobrevalorado, según la Estadística, respecto de 1913 en 1918 había un 6\% menos de municipios con luz de gas. El problema radica en que informa de los municipios por los que se re-

27 Fernández-Paradas, 2007.

28 El cambio de patrón de consumo del gas en beneficio de la calefacción y la cocina, se dio en los años 1920 y primera mitad de los 1930. Fernández-Paradas, 2009b, p. 126. Fernández-Paradas y Larrinaga, 2018.

${ }^{29}$ Recuérdese que entre 1916 y en 1918 la producción de gas cayó el 22\%, el número de fábricas el $26 \%$ y desaparecieron el $14 \%$ de las gasistas. 
caudó el mencionado impuesto ese año, con independencia de que terminasen o no el año con alumbrado de gas, tampoco informa de aquellos en los que se suspendió el servicio temporalmente. Durante el periodo considerado tenemos constancia de que no hubo iluminación pública de gas, desde 1916 en Alicante y Santiago, desde 1917 en Almería, Santa Cruz de Tenerife, Huelva, Tarragona, Arbós, La Unión y Alcoy, en 1918 se sumaron Cádiz, Valencia y Zaragoza. En ciudades tan importantes como Barcelona y Sevilla este servicio se suspendió temporalmente ${ }^{30}$. Y en la mayoría hubo una reducción considerable del servicio ${ }^{31}$. Un problema que afectó a otras ciudades europeas ${ }^{32}$.

\section{Cuadro 5}

Número de municipios con alumbrado de gas y cantidades cobradas por consumo de gas en España (1913-1918).

Pesetas $1913=100 *$

\begin{tabular}{c|rr|r|r|rr}
\hline Años & $\begin{array}{c}\text { N. }{ }^{\circ} \text { municipios } \\
\text { con alumbrado } \\
\text { gas }\end{array}$ & $\begin{array}{c}\text { Ingresado } \\
\text { por consumo } \\
\text { de particulares }\end{array}$ & $\begin{array}{c}\text { Ingresado } \\
\text { por consumo } \\
\text { de ayuntamientos }\end{array}$ & \multicolumn{2}{|c}{$\begin{array}{c}\text { Total ingresado } \\
\text { por consumo } \\
\text { de gas }\end{array}$} \\
\hline 1913 & 66 & 100 & & & $14.457 .143,03$ & 100 \\
1914 & 67 & 101 & & & $13.554 .136,64$ & 94 \\
1915 & 64 & 97 & $10.668 .315,82$ & $3.805 .193,27$ & $14.473 .509,09$ & 100 \\
1916 & 64 & 97 & $9.279 .835,23$ & $2.815 .171,50$ & $12.095 .006,73$ & 87 \\
1917 & 62 & 94 & $8.122 .689,34$ & $1.943 .579,66$ & $10.066 .269,00$ & 70 \\
1918 & 62 & 94 & $4.770 .910,66$ & $851.981,11$ & $5.622 .891,77$ & 39 \\
\hline
\end{tabular}

* 1913=100 se aplica para el número de municipios y el total ingresado por consumo de gas.

Fuente: Dirección General de Propiedades e Impuestos, Años 1913-1918. Elaboración propia.

En cuanto a los ingresos por consumo de gas (Cuadro 5), apenas hubo cambios entre 1913 y 1915, lo que confirmaría nuestra apreciación an-

30 AHFGNF, Actas de las Juntas Generales de Accionistas de Catalana de Gas y Electricidad, 29 de mayo de 1918. Dirección General de Propiedades e Impuestos, Años 19131918. García de la Fuente, 1984, p. 336. González Vergara, 2016. En Barcelona, Catalana de Gas y Electricidad dejó de suministrar gas unos días. Fàbregas, 2015, p. 141.

31 Por ejemplo, véase el caso de Málaga en Fernández-Paradas, 2011, p. 103.

32 Al respecto, el caso de Lisboa, en Cardoso de Matos, 2009, p. 75. 
terior: la crisis apenas se dejó notar en los años 1914-1915. Su caída comenzó con fuerza en 1916 y se acentuó en 1917-1918, en este último año fueron un $61 \%$ inferiores a los de 1913. ¿Cómo se repartían los ingresos en 1915?: el 73,61\% de particulares y el $26,39 \%$ de ayuntamientos. Conforme avanzó el conflicto mundial, ambos decrecieron, con mayor intensidad los de los consistorios, es decir, el alumbrado público. En 1915, las compañías de gas cobraron 10,6 millones de pesetas a sus clientes particulares, en 1918 sólo 4,7 millones, un 55,1\% menos. A los municipios, en 1915 cobraban 3,8 millones de pesetas, en 1918 fueron 0,8 millones de pesetas. Es decir, los ingresos a particulares mermaron más del 55\%, los procedentes de los ayuntamientos un 79\%. En la caída de estos últimos hubo dos municipios claves, Barcelona y Madrid vieron reducir drásticamente su factura de luz de gas $^{33}$. Por ejemplo, el consistorio barcelonés pasó de abonar 986.407 pesetas en 1915 a 21.569 en 1918 .

A nivel regional, en 1915 Madrid fue la región que más gastó en iluminación pública de gas (1.205.786,20 pesetas), seguida de cerca por Cataluña con $1.025 .566,35$, y a mayor distancia por Andalucía $(697.608,74)$ y Valencia (210.376,58). El resto de regiones, salvo Aragón, desembolsaron menos de 100.000 pesetas. En ese año Canarias, Extremadura, La Rioja y Logroño no disfrutaron de este servicio, situación que se mantuvo hasta el final de la I Guerra Mundial. A estas tres regiones se sumó Aragón en 1918. En 1916, se desplomaron los gastos por este concepto en Cataluña, que sumaron 43.918,90 pesetas. Por el contrario, los de Madrid y Andalucía crecieron, situándose en 1.354.508,80 y 731.659,30 respectivamente. Las siguieron por volumen de gastos, Cantabria con 137.725,10 pesetas y Valencia con $28.588,70$ pesetas. En 1917 constatamos una caída generalizada en todas las regiones, que tuvo su materialización más clara en el retroceso del gasto de Madrid y Andalucía. En el primero caso, en ese año gastó $817.769,20$ pesetas, un 30\% menos que en 1916. En Andalucía, fueron 435.278 .49 , un $40 \%$ menos que en 1917. El resto de las regiones, salvo Murcia, no desembolsaron más de 100.000 pesetas. En 1918, continuó mermando en todas las regiones. La que más gastó fue Madrid

${ }^{33}$ En 1917, ante la falta de carbón, el municipio de Barcelona acordó instalar un sistema mixto de alumbrado público de gas y electricidad. Arroyo, 1996, p. 322. Sobre la reducción de la factura por luz de gas en otros municipios, puede consultarse: Fernández-Paradas, 2015a, pp. 162-163. Un retroceso del alumbrado público que conllevó un cada vez mayor «peso» de otros usos del gas, proceso que se consolidó en los años 1920 y la primera mitad de los 1930. Fernández-Paradas y Larrinaga, 2018. 
$(404.078,10)$, seguida por Andalucía (179.007,35), de las restantes ninguna llegó a las 100.000 pesetas. En definitiva, los ingresos de las gasistas por alumbrado público de gas experimentaron una reducción drástica que afectó a todas las regiones, especialmente a Cataluña.

En lo que se refiere al gasto por habitante por consumo de gas en España, en 1915 y 1918 fue de 0,68 y 0,26 ptas./hab. respectivamente, el de alumbrado público de 0,18 y 0,04 ptas./hab. Por territorios, en 1915, Madrid fue la provincia que más gastó en luces públicas de gas, a razón de 1,13 ptas./hab., seguida de Cataluña $(0,44)$, Islas Baleares $(0,25)$, Valencia $(0,20)$ y Andalucía $(0,17)$. En 1918 , hubo un cambio en este ranking, la primera posición la mantuvo Madrid con 0,38 ptas./hab. - un 66\% menos que tres años antes - , seguida de Andalucía $(0,10)$, Murcia $(0,09)$, Valencia $(0,07)$ y Asturias $(0,06)^{34}$.

Las causas principales de la merma de los ingresos de las empresas de gas fueron las dificultades por las que atravesaron como consecuencia de la subida de los costes laborales y de materias primas, sobre todo de carbón mineral, y por la escasez de este último. Esto es, se dispararon los costes mientras que los ingresos disminuían. La falta de carbón y el hecho de que se recurriese al de producción nacional, menos idóneo que el británico ${ }^{35}$, o incluso a otros combustibles ${ }^{36}$, dificultó ofrecer gas en las cantidades habituales antes del inicio de la guerra y su calidad se resintión ${ }^{37}$. Como consecuencia de todo ello, hubo conflictos de las compañías de gas con los ayuntamientos y el Gobierno, el cual tenía que asegurar la provisión de carbón mineral para los sectores considerados prioritarios, no sólo el gas. A estos problemas se sumó la competencia de la electricidad, por entonces más barata, que logró en ocasiones arrebatar a las empresas de gas el suministro de alumbrado público y de particulares. Veamos el problema suscitado con el carbón mineral.

34 Dirección General de Propiedades e Impuestos, Años 1915-1918.

35 En enero de 1918, José Francos Rodríguez, alcalde de Madrid, se quejaba de las malas condiciones en las que llegaba el carbón. Simón Palmer, 1989, pp. 117 y 119. En Francia, las gasistas también se quejaron del carbón suministrado por las cuencas del país. Williot, 2002, p. 5.

36 Por ejemplo, en Dénia. García de la Fuente, 2007, pp. 193-194. Lo mismo ocurrió en Italia y Francia. The Gas World, 10 de octubre de 1917. Giuntini, 2009, p. 49.

37 Por los mismos motivos, sucedió en Gran Bretaña. Peebles, 1980, p. 24. En España el empleo de carbón no idóneo y de menor poder calorífico repercutió en una menor presión del gas. AHFGNF, Actas de las Juntas Generales de Accionistas, 29 de mayo de 1918. Simón Palmer, 1989, p. 119. 
La I Guerra Mundial provocó un aumento de su consumo a nivel mundial, lo que disparó su precio, al que también contribuyeron las dificultades de las cuencas mineras de los países en conflicto para continuar con la extracción a niveles de 1913. La situación se agravó progresivamente conforme las vías de importación se fueron cerrando. El bloqueo alemán a la marina mercante británica dificultó mucho las exportaciones desde ese país hasta que en 1917 Estados Unidos ${ }^{38}$ entró en la guerra. Por su parte, el gobierno británico prohibió su transporte en barcos enemigos y de los procedentes de países neutrales, salvo que hubiese concedido permiso $^{39}$. Las complicaciones que sufrió el comercio internacional ocasionaron la subida de los fletes y el ferrocarril, lo que, a su vez, incrementó el coste de este combustible ${ }^{40}$. En España el transporte era complicado porque su demanda requería mayor número de barcos y de vagones, que no había, y cuya carencia no era posible suplir.

En relación a este asunto, sabemos que desde el inicio de la conflagración las compañías de gas tuvieron dificultades para recibir carbón al ritmo contratado. Es más, los problemas comenzaron antes del inicio de la guerra, como consecuencia de la inestabilidad política internacional. Por ejemplo, en junio de 1914 Catalana de Gas y Electricidad informaba que había contratado con la Sociedad Sindicato de Westfalia (Alemania) 100.000 toneladas de carbón para Barcelona y Sevilla a precios ventajosos, debido a que no estaba llegando el contratado en Gran Bretaña ${ }^{41}$. En

38 En mayo de 1916 Catalana de Gas y Electricidad también señalaba como otro factor a tener en cuenta la dificultad para acceder al carbón de Estados Unidos. AHFGNF, Actas de las Juntas Generales de Accionistas de Catalana de Gas y Electricidad, 30 de mayo de 1916.

39 Gaceta de Madrid, 24 de marzo de 1916. Martínez López, 2014. García Domingo, 2007, p. 128. Sobre las restrictivas medidas del gobierno británico sobre la exportación de carbones, véase Roldán y García Delgado, 1973, p. 28. Dichas restricciones hacia los países neutrales, desde principios de 1918 empezaron a suavizarse. Gaceta de Madrid, 16 de febrero de 1918.

40 Fue un problema mundial, que afectó especialmente a Europa. Para Catalana de Gas y Electricidad, AHFGNF, Explicaciones dadas por el Consejo de Administración en la Junta General de Accionistas de Catalana de Gas y Electricidad, 30 de mayo de 1916. Para Reus, Moyano, 2012a, p. 123. Para Gran Bretaña: The Gas World, 9 de enero de 1915; y Roberts, 1980, pp. 24-25. Para Italia, Gianneti, 1987, p. 21. Para Bélgica, Brion y Moreau, 2005, p. 204. Para Suiza, Paquier y Perroux, 2005, p. 511.

${ }_{41} \mathrm{Al}$ fallarle el suministro británico optó por la diversificación, también firmó contratos con las minas asturianas y con otras minas británicas. AHFGNF: Actas del Consejo de Administración de Catalana de Gas y Electricidad, 20 de junio de 114; y Explicaciones da- 
1915 el gobierno británico prohibió la exportación de carbón ${ }^{42}$. En 1916 el ayuntamiento de Santiago afirmaba que las compañías mineras no cumplían los contratos de suministro con las gasistas ${ }^{43}$. También contribuyó que el ritmo de crecimiento de extracción de carbón en las minas españolas no fue todo el deseado ${ }^{44}$, entre otras razones por el conflicto laboral de las cuencas mineras ${ }^{45}$. El problema se agravó en 1917, al cerrar el gobierno español el transporte ferroviario desde la frontera con Francia ${ }^{46}$.

En cuanto al precio del carbón, respecto de 1913, en 1914 el británico sólo aumentó el 5\%, en los siguientes años se disparó: en 1915 y 1918, el $195 \%$ y el $954 \%$ respectivamente. El asturiano subió en menor proporción. En relación a 1913, en 1914 el 10\%, en 1916 el 170\% y en 1918 en $481 \%{ }^{47}$. Por el contrario, el precio de la electricidad, si bien fue superior al de 1913 durante la Gran Guerra, a lo sumó llegó a ser un $27 \%$ mayor $^{48}$. Es decir, en términos comparativos se encareció muchísimo el gas en relación a la electricidad.

das por el Consejo de Administración en la Junta General de Accionistas de Catalana de Gas y Electricidad, 29 de abril de 1915.

42 The Gas World, 8 de mayo de 1915.

${ }^{43}$ La factoría de Santiago dejó de producir gas en abril de 1916. Martínez (coord.), Mirás y Lindoso, 2009, pp. 268-269 y 271. Otros ejemplos de desabastecimiento de carbón en: Matos, 2005, p. 275; Pérez Serrano, Román Antequera, Villatoro Sánchez y Serrano Araujo, 2013, pp. 10-11; y Aubanell, 2014.

${ }_{44}$ Pese a que la producción de carbón mineral pasó de 3.909,8 miles toneladas en 1913 a 6.385,2 en 1918. En 1913 la suma de producción de carbón nacional más importaciones fue de 7.284,9 miles de toneladas, en 1918 7.773,5. Por tanto, las importaciones cayeron en picado. Coll, 1987, pp. 327-328 y 354-355.

45 Simón Palmer, 1989, p. 117. Fernández-Paradas, 2015b, p. 97. El aumento de la extracción de carbón se hizo a costa de disminuir la productividad de las minas. Sudrià $\mathrm{i}$ Triay y Bartolomé Rodríguez, 2010, pp. 60-61. Moyano, 2012a, p. 121. En Francia también hubo conflicto laboral en las minas por subidas salariales. Beltran y Williot, 2009, p. 92. Lo mismo sucedió en Australia y Gran Bretaña. En este país se enfrentaron a la falta de trabajadores porque fueron movilizados al frente. AHFGNF, Actas de las Juntas Generales de Accionistas de Catalana de Gas y Electricidad, 29 de mayo de 1915. Roberts, 1983. Broomham, 1987.

46 Moyano, 2012b, p. 167.

47 Coll, 1987. Sobre el precio del carbón en las fábricas de gas, pueden consultarse, por ejemplo, los de Sevilla y Reus: González García, 1981, p. 164; y Moyano, 2012a, p. 120. Es de reseñar que el coste del carbón británico consumido en Gran Bretaña subió un $82 \%$ entre 1914 y 1918, años en los que el gobierno controló los precios. En el último año de la guerra el gobierno permitió un adecuado incremento del precio de venta, pero en 1920, de nuevo impuso su control. Williams, 1981, p. 52.

48 Fernández-Paradas, 2009a, p. 94. Martínez y Mirás, 2012, p. 137. 
El Gobierno español, ante el desabastecimiento de carbón y su encarecimiento, intervino para solventar el problema. Tomó diversas medidas, algunas de las cuales afectaron negativamente al sector gasista, especialmente al alumbrado público de gas. Muy poco después del inicio de la Gran Guerra, el 11 de agosto de 1914 ordenó a las sociedades de minas que le informasen del precio del carbón. Asimismo, que expusiesen las medidas que considerasen oportunas para evitar el desabastecimiento ${ }^{49}$. La Ley de 18 de febrero de 1915 facultó al Gobierno para reducir o suprimir temporalmente los aranceles de sustancias alimenticias de primera necesidad y materias primas, cuando fuese preciso, ya fuese para el abastecimiento del consumo o las industrias. Igualmente, le autorizó a gestionar con las empresas ferroviarias la rebaja de las tarifas de transporte que se estimasen necesarias para cumplir los objetivos de la ley, si no fuese posible obligarlas a aceptar dicha reducción o si su aplicación las perjudicase, el Gobierno podría indemnizarlas económicamente ${ }^{50}$. También lo facultó para tomar las decisiones que considerase pertinentes en relación a los barcos españoles, antes de la guerra dedicados al comercio nacional, a fin de lograr que continuasen con esa actividad, y la regularización de los fletes. Esto indicaría que barcos nacionales se estarían dedicando al transporte internacional, más lucrativo ${ }^{51}$. A finales de 1915 aprobó la creación de una Junta Central ${ }^{52}$ para que analizase las necesidades de carbón de las industrias con la finalidad de solventar el déficit que pudiese resultar por la disminución de las importaciones de carbón extranjero. Para ello, dicho

49 Gaceta de Madrid, 15 de agosto de 1914.

50 Más adelante, en agosto de 1916, una Real Orden quiso mejorar el transporte de carbón por ferrocarril y el problema suscitado porque hubiese muchos vagones en Barcelona porque el carbón transportado en ellos no lo habían querido recibir las personas a quienes iba dirigido por su mala calidad. Para ello, estableció que las compañías debían elaborar un documento en el que informasen de las minas de donde procedía para que cuando la calidad del producto no fuese la acordada se pudiese reclamar a la sociedad minera. Gaceta de Madrid, 19 de agosto de 1916. En mayo de 1918 Catalana de Gas y Electricidad se quejaba de que este problema persistía. AHFGNF, Actas de las Juntas Generales de Accionistas de Catalana de Gas y Electricidad, 29 de mayo de 1918.

${ }^{51}$ Gaceta de Madrid, 19 de febrero de 1915. Sobre la preferencia de los buques españoles por el comercio internacional en detrimento del de cabotaje, véase Valdaliso, 1991, p. 130 .

${ }^{52}$ En las que estarían representados el Gobierno, el Consejo de Minería, la Comisión de estudio de la riqueza hullera nacional, las cámaras de comercio e industria de Madrid y las empresas productoras y consumidoras de carbón. Gaceta de Madrid, 4 de diciembre de 1915. 
organismo recabaría información sobre la procedencia del carbón foráneo, la producción y el consumo del nacional, las condiciones de su transporte hasta los centros de consumo y su precio ${ }^{53}$. En marzo de 1916, el Gobierno constituyó la Junta de Transportes Marítimos para que estudiase la regulación del transporte marítimo de «los artículos indispensables a la vida nacional, principalmente el trigo y el carbón», dicha intervención consistiría en fijar el precio de los fletes para la importación de estos productos, así como «recibir, clasificar y despachar» su importación y su precio máximo de venta ${ }^{54}$.

Estas decisiones no lograron que mejorase la situación, es más, empeoró. ¿Cómo reaccionaron las gasistas como colectivo ante esta problemática? En marzo de 1915 se reunieron en Sevilla representantes de las empresas de gas y electricidad para tratar el asunto. En la reunión acordaron enviar un escrito al Consejo de Ministros en que pidieron autorización para incrementar el precio del gas y la electricidad, sin que a la subida se le aplicase el impuesto del 17\% sobre el consumo de los mismos. Su propuesta recibió una respuesta negativa ${ }^{55}$. Además, el Gobierno tomó medidas que las perjudicaron de manera directa ${ }^{56}$. En ese mismo año, una Asamblea General de Gasistas celebró otra reunión en Madrid en la que acordó enviar una carta al Gobierno para explicar su angustiosa situación y pedirle que tomase medidas, que tampoco surtió efecto. Parece que a principios de 1918 de nuevo se reunió en la capital con el mismo resultado ${ }^{57}$.

Mediante el Real Decreto del 15 de julio de 1916, el Gobierno acordó que obligatoriamente se suprimiese el alumbrado público, desde las once de la noche, en todos los ayuntamientos donde fuese de gas o electricidad, si se produjese con carbón. Asimismo, que los consistorios

53 Gaceta de Madrid, 4 de diciembre de 1915.

${ }^{54}$ De la que formarían parte representantes de los Ministerios de Marina y de Gobernación, la Cámara Oficial de Comercio de Madrid, la de Industria de Barcelona y asociaciones nacionales, entre ellas la de Navieros Españoles y la de Navieros y Consignatarios de Barcelona. Gaceta de Madrid, 4 de marzo de 1916.

55 Fernández-Paradas, 2015a, p. 159.

56 Ahora bien, hay que decir que disponemos de noticias que demuestran que el Gobierno intentó que llegase carbón a algunas fábricas de gas. Por ejemplo, a finales de 1917 la Junta de Tráfico Marítimo requisó el barco Elvira para llevar su cargamento de carbón para las fábricas gaditanas. Fernández-Paradas, 2015a, p. 159.

57 AHFGNF: Actas del Consejo de Administración de Catalana de Gas y Electricidad, 26 de enero de 1916; y Explicaciones dada por el Consejo de Administración en la Junta General de Accionistas de Catalana de Gas y Electricidad, 29 de mayo de 1918. 
acordasen con las compañías de alumbrado público las rebajas en la factura del gas que de ello se derivasen, teniendo en cuenta la disminución del consumo de luz y el precio de los carbones que adquiriesen las factorías con destino a dicho servicio ${ }^{58}$. Esta medida dañaba a las gasistas y centrales eléctricas que utilizaban carbón, no a las eléctricas que recurrían al agua como fuente de energía. De ahí que afectase en mayor medida al sector del gas.

Las compañías de gas y los ayuntamientos se opusieron ${ }^{59}$. Los municipios porque no querían que se redujese el alumbrado público por motivos de seguridad. Las gasistas porque pretendieron incrementar las tarifas de gas para compensar la pérdida de ingresos, pretensión que los consumidores y los municipios rechazaban. Hubo ayuntamientos que si bien en un primer momento acordaron la reducción del alumbrado, posteriormente se retractaron o intentaron no aplicarla totalmente. Las compañías de gas quisieron negociar con los consistorios el montante de la factura de alumbrado. Lo cual no era fácil porque en teoría debería bajar al reducirse las horas de servicio, pero el incremento del precio del carbón contribuía a que aumentase ${ }^{60}$. Pese a ello, lo habitual fue que ambas partes llegasen a un acuerdo sobre la cantidad a abonar por los municipios, también que las empresas de gas conforme constataron que no podían asegurar el alumbrado de gas, accediesen a la sustitución de parte de las luces de gas por lámparas eléctricas ${ }^{61}$. En otras ocasiones, como hemos explicado, conllevó la supresión temporal o definitiva de los faroles de gas.

Algunos ayuntamientos, como los de Córdoba, Barcelona y Madrid se plantearon la municipalización del servicio ${ }^{62}$. La materialización de estas

58 Gaceta de Madrid, 18 de julio de 1916. Una medida similar se tomó en Lisboa. Cardoso de Matos, 2009, p. 75.

59 También se opusieron los industriales y los comerciantes. Por ejemplo, en Córdoba la Cámara de Comercio e Industria y la Unión Industrial por los intentos de robos ocurridos tras la supresión del alumbrado a partir de las 12 de la noche. Fernández-Paradas, 2009a, p. 98.

${ }^{60}$ Fernández-Paradas, 2009a, p. 98.

61 Arroyo, 1996, p. 322. Martínez (Coord.), Mirás y Lindoso, 2009, p. 270. Pérez Serrano, Román Antequera, Villatoro Sánchez y Serrano Araujo, 2012, p. 12. FernándezParadas, 2015a, p. 159.

62 Arroyo, 1996, p. 367. Fernández-Paradas: 2009a, pp. 105-108; 2009b, p. 116; y 2015 b p. 65 . Una corriente municipalizadora que también se dio en otros países europeos durante la I Guerra Mundial. Por ejemplo, en Portugal y Francia. Arroyo y Cardoso de Matos, 2009. Goodall, 2005, p. 476. Fernandez, 2005, p. 333; y 2015, pp. 21-33. 
propuestas era complicada, sobre todo por sus dificultades financieras que les impedía compensar económicamente a las gasistas por la municipalización ${ }^{63}$. De estas iniciativas, únicamente se hizo realidad en Madrid, su consistorio incautó a la Compañía Madrileña de Alumbrado y Calefacción por Gas la factoría en 1917 con el razonamiento de que el servicio se había deteriorado y había que asegurar el suministro a la ciudad, en peligro por las dificultades de aprovisionamiento de carbón ${ }^{64}$.

El enfrentamiento de las compañías de gas con el Gobierno fue más intenso. Reclamaron subidas de tarifas ${ }^{65}$ y amenazaron con suspender el suministro de gas. El Gobierno reaccionó aprobando el real decreto de 12 de septiembre de 1916 que prohibió a los productores de gas y electricidad para alumbrado suspender o cesar el servicio contratado con las corporaciones municipales, sin autorización previa del gobierno civil, la cual podría denegarse cuando pudiese provocar «graves alteraciones del orden público» ${ }^{66}$. El Gobierno las obligó a cumplir la normativa sobre reducción del alumbrado, argumentando que se estaban agotando las reservas de carbón y no llegaba del exterior ${ }^{67}$.

Si avanzamos en el tiempo, constatamos el fracaso del Gobierno en solventar el problema con el carbón. Prueba de ello es que dio un paso más en la intervención de los sectores minero y gasista con la Ley de Subsistencias de 11 de noviembre de 1916, que permitió al Gobierno en relación a los combustibles, entre ellos el carbón, a «incautar y explotar las minas, las fábricas de gas y los productos en ellas obtenidos y las instalaciones carboníferas de todo género, si no dieren resultado eficaz otras medidas para obtener la normal cotización de sus productos». Asimismo, consideró de utilidad pública «la expropiación de las substancias alimenticias y de primeras materias» ${ }^{68}$. Esta disposición supuso un hito, pues permitió por primera vez la incautación de las factorías de gas si no fuese posible controlar el precio del gas y sus subproduc-

63 En cuanto al marco legal sobre la municipalización, destaca la Real Orden de 23 de julio de 1907 que estableció las condiciones que el ayuntamiento de Valencia tendría que cumplir para la municipalización. Sobre este asunto, pueden consultarse: Fernández-Paradas, 2009b, 2015b, p. 65; y Magaldi, 2017. El caso francés, Fernandez, 2015.

${ }^{64}$ García de la Fuente, 1984. Dirección General de Propiedades e Impuestos, Años 1920-1921. Fernández-Paradas y Larrinaga, 2018.

65 Véase el ejemplo de Madrid, en Simón Palmer, 1989, p. 117.

66 Gaceta de Madrid, 13 de septiembre de 1916.

67 Fernández-Paradas, 2009a, pp. 98-99.

68 Gaceta de Madrid, 12 de noviembre de 1916. 
tos. Ahora bien, también hay que reconocer que intentó asegurar la llegada de carbón a las fábricas. Al respecto, cabe señalar que en marzo de 1917 aprobó, en relación a los carbones, que primero serían considerados transportes preferentes los destinados a los ferrocarriles y luego los dirigidos al alumbrado público de gas. Correspondería a las ferroviarias asegurarse de disponer de los vagones necesarios para llevar el carbón a este último destino ${ }^{69}$. En agosto de 1918, poco antes de terminar la Guerra, persistían las dificultades, lo que justificó que la Comisaría General de Abastecimientos ${ }^{70}$ ordenase que el reparto del carbón se realizaría teniendo en cuenta su destino. Para ello fijó los siguientes grupos: a) Marina de guerra y servicios del Estado; b) Ferrocarriles; c) Marina mercante; d) Factorías de gas y electricidad; e) industrias «sujetas a tasa»; f) «industrias libres»; y g) consumo doméstico. También estableció que los suministros correspondientes a los grupos a, b, c y d, es decir, incluía la industria gasista, se efectuarían directamente por el Comité de Distribución de Carbones $^{71}$, que concedería a cada uno de ellos la cantidad de carbón, nacional o extranjero, teniendo en cuenta la disponibilidad y sus necesidades ${ }^{72}$.

Otro de los problemas a los que se enfrentaron las compañías de gas fue la conflictividad laboral que ocasionó un aumento de los costes, que sumado a los del carbón y a la pérdida de ingresos en favor de las eléctricas, provocó una caída de los beneficios e incluso pérdidas. Veamos algunos ejemplos de estas protestas. En agosto de 1918 tuvo lugar en Córdoba un movimiento huelguístico con participación de los obreros de la fábrica de gas, que exigían la jornada de ocho horas, estabilidad en el empleo para el personal con una antigüedad de seis meses y subida salarial, lograron esta última ${ }^{73}$. La presión de los trabajadores estuvo detrás del incremento de salarios de los empleados de Gas

69 Además, no sabemos desde que momento el Gobierno consiguió que la Compañía de los Ferrocarriles del Norte dedicase 315 vagones al embarque de carbones en los puertos de Asturias, destinados exclusivamente a producir luz. Gaceta de Madrid, 14 de marzo de 1917.

${ }^{70}$ Fue creada por el Gobierno el 1 octubre de 1917. Gaceta de Madrid, 4 de octubre de 1917.

${ }^{71}$ Este organismo fue creado el 17 abril de 1918 para asegurar el abastecimiento y regular la distribución de los carbones minerales. Gaceta de Madrid, 19 de abril de 1918.

72 Gaceta de Madrid, 7 de agosto de 1918.

73 Fernández-Paradas, 2009a, p. 97. 
Reusense, lo mismo sucedió en la factoría de Catalana de Gas y Electricidad de Sevilla ${ }^{74}$.

Un escollo de gran envergadura fue la competencia con las eléctricas, que se acentuó durante la Gran Guerra, debido a que, como comentamos, las empresas de gas no podían competir con la electricidad generada en los grandes saltos de agua, mucho más barata que el gas. Estas centrales solo estaban al alcance de sociedades españolas de gran tamaño, que podían acometer inversiones tan cuantiosas. Desde comienzos del novecientos, el Gobierno aprobó una legislación que pretendía complicar la presencia del capital extranjero. En el periodo que nos ocupa destaca la Ley de 2 de marzo de 1917, que impedía a las compañías foráneas y a los extranjeros acceder a nuevas concesiones de servicios públicos, así como a su dirección. Lo que dificultó a las gasistas acceder o profundizar en el negocio de la electricidad ${ }^{75}$.

Hasta principios del siglo Xx la estrategia desplegada por las compañías de gas $^{76}$, basada en la introducción de avances tecnológicos, las guerras de precios y la entrada en el negocio eléctrico dio resultados positivos. Sin embargo, aproximadamente a partir de 1910 no fueron suficientes, cuando las mejoras tecnológicas del sector eléctrico ${ }^{77}$ convirtieron a la electricidad en un producto fiable y más económico. Como hemos visto, a las empresas de gas durante la conflagración no les quedó otra opción que dejar de suministrar alumbrado por gas en bastantes poblaciones, mercado que ocupó la electricidad de las propias compañías de gas ${ }^{78}$ o de las eléctricas ${ }^{79}$. En ocasiones, las gasistas llegaron a acuerdos con sus competidoras que les resultaron favorables ${ }^{80}$.

De todas las empresas de gas, Catalana de Gas y Electricidad fue la que apostó con más fuerza por la electricidad. Por entonces, empezó su

${ }^{74}$ González García, 1981, p. 164. F. Moyano: 2012b, p. 171; y 2012a, p. 122. El alza salarial también afectó a las industrias gasistas de otros países, véase lo sucedido en Gran Bretaña y Bélgica en: Roberts, 1983; y Brion y Moreau, 2005, p. 204.

75 Fernández-Paradas y Larrinaga, 2018.

76 En algunos casos, también fue clave una inteligente gestión empresarial. Sobre las estrategias de gasistas y eléctricas, puede consultarse: Fernández-Paradas, 2005, pp. 608-614.

77 Fernández-Paradas, 2005, pp. 613-614.

78 Por ejemplo, así ocurrió en Santiago. Martínez (coord.), Mirás y Lindoso, 2009, p. 269.

79 Recuérdese lo sucedido en Galicia.

${ }^{80}$ Fàbregas, 2015, pp. 144-145. 
estrategia para producir hidroelectricidad a gran escala. En 1911, en Cataluña el capital extranjero ${ }^{81}$ constituyó sociedades para explotar recursos hidroeléctricos. Catalana de Gas y Electricidad no podía permanecer impasible solo con la termoelectricidad, ese mismo año fundó la Sociedad General de Fuerzas Hidroeléctricas, aportando el 38\% del capital ${ }^{82}$. En 1912 la absorbió y compró a la Compañía Lebon el 50\% de la Central Catalana de Electricidad, es decir, se hizo con el control total de esta empresa y la sociedad francesa abandonó el negocio de la electricidad en Barcelona. Ese mismo año Catalana de Gas y Electricidad y Energía Eléctrica de Cataluña negociaron un acuerdo de fusión que fracasó. Un año después, esta última pasó a estar bajo control de Barcelona Traction. Como hemos dicho, en 1913 Catalana de Gas y Electricidad adquirió La Propagadora del Gas y La Energía. También comenzó las obras de la central hidroeléctrica del Seire, sobre el río Ésera, afluente del Cinca, situado en el altoaragón. Empero, la Gran Guerra retrasó la adquisición de sus equipos eléctricos en el exterior demorando la puesta en funcionamiento de la central ${ }^{83}$. La conflagración también generó dificultades para comprar carbón, que también afectaron a sus centrales térmicas de producción de electricidad. Según Pedro Fàbregas, las fuertes inversiones realizadas originaron un nivel de apalancamiento excesivo ${ }^{84}$.

En definitiva, las gasistas se enfrentaron a un escenario muy complejo, caracterizado por el desorbitado aumento de los costes, el desabastecimiento

81 Nos referimos a la Barcelona Traction Light \& Power - La Canadiense - y la Energía Eléctrica de Cataluña, creada por capital galo, representado por Compagnie Gènérale d'Electricité, Schweizerische Gessellschaft für Elektrische Industrie, que era el banco suizo de Siemens, y los catalanes, Emilio Riu y Cristóbal Massó, que contribuyeron con concesiones hidráulicas. Fàbregas, 2014.

${ }^{82}$ El restante fue aportado por Bertand e Hijo, dedicada a la actividad textil, y Eugenio López de Tudela y Francisco Bastos que aportaron concesiones de saltos de agua. Fàbregas, 2014. En ese año de 1911 Catalana de Gas y Electricidad sufrió un serio revés, al no hacerse con la contrata de alumbrado eléctrico de Barcelona, que recayó en la Compañía Barcelonesa de Electricidad, fundada en 1894 por la alemana Allgemeine Elektrizitätas Gessellschaft (AEG). Muro Morales, 2012,p. 22.

${ }^{83}$ Por el mismo motivo tuvo dificultades para poner en marcha la central térmica de San Adrián del Besos. Finalmente montó «una sala de calderas y un grupo generador», de esta manera se convirtió en central de reserva de las centrales hidroeléctricas. AHFGNF: Actas del Consejo de Administración de Catalana de Gas y Electricidad, 14 de octubre de 1914; y Actas de las Juntas Generales de Accionistas de Catalana de Gas y Electricidad, 31 de mayo de 1917 y 29 de mayo de 1918.

${ }^{84}$ Fàbregas, 2014. 
de carbón, la reducción de la mitad del alumbrado público, la pérdida de ingresos $^{85}$, y la competencia de la electricidad. El resultado fue la caída de los beneficios empresariales que en ocasiones se tornaron en negativos.

\section{Cuadro 6}

Beneficios de empresas de gas en España (1914-1918). Pesetas*

\begin{tabular}{|c|c|c|c|c|c|}
\hline Empresas/Años & 1914 & 1915 & 1916 & 1917 & 1918 \\
\hline Catalana de Gas y Electricidad & 4.191 .516 & 3.001 .798 & 1.364 .024 & -3.000 .000 & -3.000 .000 \\
\hline $\begin{array}{l}\text { Compañía Madrileña de Alumbrado } \\
\text { y Calefacción por Gas }\end{array}$ & 496.988 & 461.289 & 168.918 & -472.946 & -1.416 .068 \\
\hline $\begin{array}{l}\text { Compañía Popular de Gas y Electri- } \\
\text { cidad de Gijón }\end{array}$ & 558.059 & 558.059 & 573.925 & 559.602 & 628.248 \\
\hline Gas Reusense & 115.683 & 73.633 & 53.381 & -5.243 & 8.032 \\
\hline La Propagadora de Gas en Badalona & 107.704 & 73.674 & & & \\
\hline $\begin{array}{l}\text { Sociedad Cooperativa Gaditana de } \\
\text { Fabricación de Gas }\end{array}$ & 121.673 & 117.400 & 28.074 & $-384,60$ & -181.661 \\
\hline $\begin{array}{l}\text { Société Anonyme des Villes de Co- } \\
\text { rogne et Vigo }\end{array}$ & $147.219,90$ & & 18.429 & & \\
\hline $\begin{array}{l}\text { Sociedad de Gas y Electricidad de } \\
\text { Santiago }\end{array}$ & 136.026 & 142.332 & 145.440 & 148.725 & 172.008 \\
\hline Sociedad Popular Ovetense & 264.948 & s.d. & 284.527 & 316.419 & 470.807 \\
\hline
\end{tabular}

* En el caso de La Propagadora de Gas desconocemos la cifra de beneficios en los años 1916-1918, lo mismo sucede con la Société Anonyme des Villes de Corogne et Vigo para 1915 y 1917, en 1918 había desaparecido. Sí sabemos que ambas sufrieron pérdidas durante esos años.

s.d. sin datos.

Fuente: Riu Yferiquet (dir.) (1920); y Fàbregas, 2015: elaboración propia.

El Cuadro 6 muestra la evolución de los beneficios empresariales de nueve empresas de gas representativas del sector - de pequeño, mediano

85 A la merma de ingresos habría que añadir el perjuicio ocasionado por la deuda municipal acumulada por impago de la factura del gas. Martínez (coord.), Mirás y Lindoso, 2009 , p. 301. 
y gran tamaño, españolas y foráneas - . La tendencia general fue a una reducción de los beneficios ${ }^{86}$ en 1915 respecto de 1914, especialmente significativa fue la merma experimentada por los de Catalana de Gas y Electricidad, del orden del 25\%. En 1915, a falta de los datos de la Sociedad Popular Ovetenses, solo la Société Anonyme des Villes de Corogne et Vigo tuvo pérdidas. En 1916, los beneficios continuaron decreciendo, sobre todo los de la Compañía Madrileña y Catalana de Gas y Electricidad, los de esta última fueron casi un 69\% inferiores a los de 1914. De las compañías recogidas en el Cuadro 6, más de la mitad tuvieron pérdidas, muy cuantiosas en los casos de Catalana de Gas y Electricidad, la Compañía Madrileña y la Cooperativa Gaditana ${ }^{87}$. Otra conclusión a reseñar es que las compañías que obtuvieron beneficios más elevados se situaban en el norte del país, seguramente la proximidad con las minas de carbón asturianas las benefició.

\section{Conclusiones}

La I Guerra Mundial supuso un serio revés para la industria gasista española, especialmente para el alumbrado de gas, sobre todo como consecuencia del desabastecimiento de carbón y su encarecimiento. Los datos elaborados en este estudio demuestran que en general el sector comenzó a notar con fuerzas los efectos negativos a partir de 1916, las cuales se fueron agravando en los años 1917 y 1918. La producción de gas, el número de empresas y de fábricas empezó a reducirse de manera importante a partir de 1916, afectando esta caída cronológicamente primero a la generación de gas.

Esta crisis provocó una mayor concentración de la actividad gasista a nivel territorial, en beneficio de Cataluña, sobre todo el mercado de la provincia de Barcelona, que parece soportó mejor la crisis, al menos en términos comparativos. En 1918 Cataluña había aumentado su contribución al conjunto al sector, al sumar casi el 73\% de la producción del país. Por el contrario, Andalucía y Madrid perdieron «peso».

${ }^{86}$ De este listado de empresas, solo Popular de Gas y Electricidad de Gijón mantuvo los beneficios e incluso los aumentó en 1918.

87 Otro aspecto poco estudiado son las deudas de las gasistas. Las de la Cooperativa Gaditana experimentaron un espectacular incremento durante la Gran Guerra. FernándezParadas, 2015a, p. 166. 
Como era de esperar, soportaron peor la crisis las pequeñas empresas que solían abastecer solo a un municipio, también las extranjeras, que perdieron buena parte de su cuota de producción, algunas de la cuales pasaron a manos de capital español. Hay que reseñar la pérdida de relevancia de las dos grandes compañías foráneas, la Compañía Lebon y La Madrileña de Alumbrado, cuya participación en la producción total de gas retrocedió considerablemente.

Los ingresos del sector por consumo de gas muestran que la crisis fue mayor de lo mostrado por otros indicadores, en 1918 fueron dos tercios inferiores a los de 1913. Un retroceso que afectó en mayor medida a los procedentes del alumbrado público, los cuales en 1918 fueron un $79 \%$ menores a los de 1915. A nivel regional, en este último año, Madrid y Cataluña fueron los territorios que más dinero destinaron a iluminación pública, seguidos a distancia por Andalucía y Valencia. En 1916 se desplomó el gasto de Cataluña a niveles muy bajos. En 1918 había tenido lugar un cambio sustancial en el reparto del gasto en luces públicas de gas, por entonces, las regiones que concentraron la mayor parte del mismo fueron Madrid y Andalucía.

Diversos factores contribuyeron a la caída de los ingresos de las compañías de gas. La subida de los costes - laborales y de materias primas-, la falta de carbón, la decisión tomada por el Gobierno de reducir a la mitad el alumbrado público generado con carbón, así como la competencia de las eléctricas, que en términos comparativos ofrecían un producto mucho más barato.

Las empresas de gas tuvieron conflictos con el Gobierno y los ayuntamientos. El Gobierno tuvo que intervenir en la economía para evitar el desabastecimiento de carbón y que su precio continuase incrementándose. Para lograrlo, intentó regularizar los transportes marítimo y ferroviario, para lo que creó organismos encargados de esta tarea, los cuales, pese a que contemplaron las necesidades de la actividad gasista entre las prioritarias, fracasaron en su cometido. A las compañías de gas les perjudicó que desde julio de 1916 el Gobierno obligase a los consistorios a reducir a la mitad el alumbrado público, lo que se tradujo en la caída de sus ingresos por este concepto. Los consistorios se resistieron a implementar esta medida porque perjudicaba a la seguridad ciudadana. Las gasistas reaccionaron solicitando aumentos de tarifas y amenazando con suspender temporal o definitivamente el servicio. El Gobierno intentó impedir el corte del suministro, que requería permiso del gobierno civil. Pese a ello, muchas fábricas dejaron de producir gas por falta de carbón. En este proceso de 
intervención del Gobierno en el sector gasista hay que reseñar la Ley de Subsistencias de 11 de noviembre de 1916 porque permitió, por primera vez, la incautación de factorías de gas si no fuese factible controlar el precio del gas y sus subproductos.

El conflicto suscitado entre las empresas de gas y los municipios por la reducción del alumbrado público de gas, obligó a calcular la factura de estos faroles. Aunque al principio las posiciones de ambas partes parecían muy alejadas, en general la disputa se solventó mediante un acuerdo sobre su coste. Además, las compañías de gas conforme fueron conscientes de que no podían garantizar el suministro de gas acordaron con los ayuntamientos el remplazo de parte de las luces de gas por las eléctricas, operación de la que en ocasiones se encargaron las eléctricas. En menos ocasiones, los consistorios valoraron la posibilidad de municipalizar la factoría de gas, medida que solo se aplicó en Madrid.

El exorbitado incremento de los costes laborales y de carbón, sumado a la caída de los ingresos, ocasionaron el retroceso de los beneficios que se tornaron en pérdidas en 1917-1918, que afectaron en torno a la mitad de las gasistas analizadas. En definitiva, la industria del gas sufrió una aguda crisis durante la I Guerra Mundial, que perjudicó con mayor intensidad al alumbrado público de gas.

\section{Bibliografía}

Arroyo, M., La industria del gas en Barcelona (1841-1933), Ediciones del Serbal, Barcelona, 1996.

ARroyo, M., «Banca, infraestructuras urbanas y estrategias empresariales. La fábrica de gas de Málaga (1923-1940)», en Actes del 3. ${ }^{\text {er }}$ Congreso de historia catalano-andaluza, Cataluña y Andalucía, 1898-1939, Ediciones del Serbal, Barcelona, 2001, pp. 297-325.

Arroyo, M. «El gas de Madrid y las compañías de crédito extranjeras en España, 1856-1900», Scripta Nova, VI, 131, 2002.

ARroyo, M. y CARDoso DE Matos, M., «La modernización de dos ciudades: las redes de gas de Barcelona y Lisboa (siglos XIX-XX)», Scripta Nova, XIII, 196 (6), 2009.

Aubanell, A.M. ${ }^{a}$, «La Propagadora del Gas: una empresa multimunicipi», XI Congreso Internacional de la Asociación Española de Historia Económica, Madrid, 4-5 septiembre 2014.

Bartolomé Rodríguez, I. y Girón Sierra, A., «Gas en Sanlúcar de Barrameda (1882-1920)», Revista de Historia Industrial, 71, 2018, pp. 57-87. 
Beltran, A. y Williot, J.P, Du gaz en France à Gaz de France, deux siècles de culture gazière, Le Cherche-Midi, Paris, 2009.

Brion, R. y MOREAU, J.-L. «Jalons pour une histoire du gaz en Belgique aux XIXe et XXe siècles», en PAQuIER, S. y WiLliot, J.-P. (dirs.), L'industrie du gaz en Europe aux XIXe et XX siécles. L'innovation entre marchés privés et collectivités publiques, Peter Lang, Bruxelles, 2005, pp. 197-224.

Broomham, R., First light 150 years of gas, Hale \& Iremonger, Sydney, 1987.

BRODER, A., Le rôle des interest économiques étrangers dans la croissance de l'Espagne au siècle XIX, Tesis Doctoral, Paris, 1981.

Carreras, A. y Tafunell, X. (2003), Historia Económica de la España Contemporánea, Crítica, Barcelona, 2003.

CARdoso de Matos, A., «Gas industry and urban modernisation: Lisbon in the 19th and 20th centuries», TST. Transportes, Servicios y Telecomunicaciones, 16, 2009, pp. 62-80.

Castro Balaguer, R., «Historia de una reconversión silenciosa. El capital francés en España, c. 1800-1936», Revista de Historia Industrial, 33, 2007, pp. 81-118.

Coll, S., «Primera Parte: 1770 a 1935», en S. Coll y C. Sudrià, El carbón en España, 1770-1961. Una historia económica, Turner, Madrid, 1987, pp. 1-545.

Comín, F., «El período de entreguerras (1914-1936)», en F. Comín, M. Hernández y E. Llopis (eds.), Historia Económica de España Siglos X-XX, Crítica, Barcelona, 2002, pp. 285-330.

Costa CAMPI, M.T.T., «Iniciativas empresariales y capitalismo extranjero en el sector servicios de la economía española durante la segunda mitad del siglo XIX», Investigaciones Económicas, 14, 1981, p. 55-57.

Dirección General De Propiedades e Impuestos, Estadística del Impuesto sobre el consumo de luz de gas, electricidad y carburo de calcio, Editada por Imprenta de la Sucesora de M. Minuesa de los Ríos para los años 19131916, Editada por la Imprenta Sobrinos de la Sucesora de M. Minuesa de los Ríos para 1917-1918, Editada por la Imprenta de la Fábrica Nacional de Moneda y Timbre para 1919-1921.

FÀbregas, P.A., La Globalización en el siglo XIX: Málaga y el gas, Ateneo de Sevilla y Universidad de Sevilla, Sevilla, 2003.

FÀbregas, P.A., «La estrategia eléctrica de Catalana de Gas y Electricidad hace cien años (1890-1930)», XI Congreso Internacional de la Asociación Española de Historia Económica, Madrid, 4-5 septiembre 2014.

FÀbregas, P.A., Gas Natural Fenosa, de Barcelona al mundo. Los primeros 170 años de historia, Gas Natural Fenosa, Barcelona, 2015.

FERNANDEZ, A., «Le gaz à Bordeaux: la dynamique d'une Enterprise locale, la Régie municipale (1919-1991)», en PAQUIER, S. y WiLliot, J.-P. (dirs.), L'industrie du gaz en Europe aux XIXe et XX siécles. L'innovation entre marchés privés et collectivités publiques, Peter Lang, Bruxelles, 2005, pp. 331-346. 
FERnANDEZ, A. «La gestión directa de los servicios urbanos técnicos en Francia en el siglo XIX», Revista de Historia de la Economía y de la Empresa, 9, 2015, pp. 21-33.

FERNÁNDEZ-PARADAS, M., «El alumbrado público en la Andalucía del primer tercio del siglo Xx: una lucha desigual entre el gas y la electricidad», Historia Contemporánea, 31, 2005, pp. 601-621.

FERnÁNDEZ-PARADAS, M. «Una fuente para el estudio del alumbrado en España: La Estadística del Impuesto sobre el Consumo de luz de gas, electricidad y carburo de calcio (1901-1934)», Biblio 3W, 12, 748, 2007.

FERnÁNDEZ-PARADAs, M., La industria del gas en Córdoba (1870-2007), Lid Editorial y Fundación Gas Natural Fenosa, Barcelona, 2009a.

FERnÁNDEZ-PARADAS, M., «Empresas y servicio de alumbrado público por gas en España (1842-1935)», TST. Transportes, Servicios y Telecomunicaciones, 16, 2009b, pp. 108-131.

FERnÁndeZ-PARAdAs, M., «The Gas Industry in Málaga (1854-2009)», Quaderns d'història de l'Enginyeria, XII, 2011, pp. 93-124.

FERnÁndez-PARADAs, M., La industria del gas en Cádiz (1845-2012), Fundación Gas Natural Fenosa, Barcelona, 2015a.

FERNÁNDEZ-PARADAS, M., «La regulación del suministro de gas en España (18411936)», Revista de Historia Industrial, 61, 2015b, pp. 49-78.

FERnÁndeZ-PARADAS, M. y LARRINAGA RodríGUEZ, C. «L'Industrie du gaz en l'Espagne dans le période de 1'entre-deux-guerres», Histoire, Economie et Societé, 3, 2018, pp. 30-46.

García de la Fuente, D. La Compañía Española de Gas, S.A. «CEGAS». Más de cien años de empresa, CEGAS, Valencia 1984.

García de la Fuente, D., La luz de gas también brilló en Dénia, Ajuntament de Dénia, Dénia, 2007.

García Domingo, E., «El impacto de la Primera Guerra Mundial en la marina mercante española: un apunte sobre el caso catalán (1914-1922», TST. Transportes, Servicios y Telecomunicaciones, 13, 2007, pp. 122-144.

Germán, L., Eléctricas Reunidas de Zaragoza (1910-1990). El desarrollo del sector eléctrico en Aragón, Instituto Fernando el Católico, Zaragoza, 1990.

Gianneti, R., «Maturità e declino del gas iluminante (1880-1920)», en CAStronovo, V., Paletta, G., Giametti, R. y Bottighieri, B, Dalla luce all'energia. Storia dell'Italgas, Editorial Laterza, Roma, 1987.

GiUnTINI, A., «La parábola del gas in Italia dal carbone al metano dalle origini ottocenteschi ad oggi. Aspetti economici, technologici et finanziari in chiave comparativa», TST. Transportes, Servicios y Telecomunicaciones, 16, 2009, pp. 38-60.

GonZÁlez García, A., El Gas en Sevilla (Cien años de historia), Artes Gráficas, Sevilla, 1981. 
GonZÁLEZ VERGARA, O., «La ciudad industrial contemporánea a la luz de la Arqueología. Generalidades, posibilidades de estudio y ejemplo murciano», La Historia, lost in translation?. XIII Congreso de la Asociación de Historia Contemporánea, Albacete, 21-23 de septiembre de 2016.

Goodall, F., Burning to served. Selling gas in competitive market, Landmark, Ashbourne, 2005.

MagALDI, N., «Los orígenes del concepto jurídico de servicio público en España a través de la municipalización del gas», en BARTOLOMÉ, I., FERnÁNDEZ-PARADAS, M. y MirÁs ARAUJO, J. (eds.), Globalización, nacionalización y liberalización de la industria del gas en la Europa latina (siglos XIX-XXI), Marcial Pons, Madrid, 2017, pp. 173-192.

MARTínEZ, A., «Empresas extranjeras de gas en España: un análisis de caso», XI Congreso Internacional de la Asociación Española de Historia Económica, Madrid, 4-5 septiembre 2014.

MARTíneZ, A., «Transición energética y capital extranjero: Huelva, 1878-1919», en BArtolomé, I., Fernández-Paradas, M. y Mirás Araujo, J. (eds.), Globalización, nacionalización y liberalización de la industria del gas en la Europa latina (siglos XIX-XXI), Marcial Pons, Madrid, 2017, pp. 215-235.

MartíneZ, A. (coord.), MirÁs, J. y Lindoso, E., La industria del gas en Galicia: del alumbrado por gas al siglo XXI, 1850-2009, Lid Editorial y Fundación Gas Natural Fenosa, Barcelona, 2009.

MartíneZ, A y J. MirÁs, «The city as a business: gas a business in the Spain region of Galicia, 1850-1936», Continuity and Change, 27, 1, 2012, pp. 125150 .

MARTíneZ, A., y Mirás, J., «Difusión y consumo de gas y electricidad para alumbrado en las urbes españolas durante la segunda transición energética (19011934)», Revista de Historia Industrial, 71, 2018, pp. 87-119.

MAtos, R., «L'industrie gazière à Tenerife (Canaries). Le rôle des capitaux allemands et helvétiques 1906-1933)», PAQuier, S. y Williot, J.-P. (dirs.), L'industrie du gaz en Europe aux XIXe et XX siécles. L'innovation entre marchés privés et collectivités publiques, Peter Lang, Bruxelles, 2005, pp. 373379.

Mirás, J., Continuidad y cambio en la España urbana en el periodo de entreguerras: Análisis de una ciudad española, Netbiblo, A Coruña, 2007.

MoYAno, F., «La hulla: auge y declive en la industria del gas catalana y española. El caso de la fábrica de gas de Reus (1854-1969)», TST. Transportes, Servicios y Telecomunicaciones, 22, 2012a, pp. 112-149.

Moyano, F., Un model d'empresa energética local: Gas Reusense (1854-1969), Fundación Gas Natural, Barcelona, 2012b.

Muro Morales, J.I., «La red eléctrica y el alumbrado público en Barcelona (1894-1922)», Simposio Internacional Globalización, innovación y construcción de redes técnicas urbanas en América y Europa, 1890-1930. Brazi- 
lian Traction, Barcelona Traction y otros conglomerados financieros y técnicos, Universidad de Barcelona, 23-26 de enero de 2012.

Paquier, S. y Perroux, H., «Naissance et développement de l'industrie gazière en Suisse. Approche nationale et exemple genevois (1843-1939)», en PAQUIER, S. y WILLIOT, J.-P. (dirs.), L'industrie du gaz en Europe aux XIXe et $X X$ siécles. L'innovation entre marchés privés et collectivités publiques, $\mathrm{Pe}-$ ter Lang, Bruxelles, 2005, pp. 509-529.

PeEbles, M.W.H., Evolution of the gas industry, Macmillan, London, 1980.

Pérez Serrano, J., Román Antequera, A., Villatoro Sánchez, F.P. y SeRRANO ARAUJO, F.J., «El servicio de alumbrado en una ciudad intermedia: el Puerto de Santa María», en Ortega LóPez, T.M. a y Del Arco Blanco, M.A. (eds.), Claves del mundo contemporáneo, debate e investigación. Actas del XI Congreso de la Asociación de la Historia Contemporánea, Comares, Granada, 2013.

Riu YFeriquet, D. (dir.), Anuario Financiero y de Sociedades Anónimas 1919, Madrid, 1920.

ROBERTS, D. E., The Northamton gas undertaking 1823-1949, East Midlands Gas, Leicester, 1980.

RoBerTs, D. E., Grimsby Gas Undertaking 1836-1949, East Midlands Gas, Leiscester, 1983.

RoldÁN, S. y García Delgado, J.L., La formación de la sociedad capitalista en España 1914-1920. Tomo II, Confederación Española de Cajas de Ahorros, Madrid, 1973.

Simón Palmer, M. aC., El Gas y los madrileños, Gas Madrid, Madrid, 1989.

Sudrià i TRYAy, C y Bartolomé Rodríguez, I., «Huguet del Villar y el valor «energético» de España», en SudRIÀ, C. y Tello, E. (eds.), El valor geográfico de España (1921). Emilio Huguet del Villar, Universitat de Barcelona, Barcelona, 2010.

The Gas World Year Book, John Allan \& Co, London, Años 1913-1919.

Valdaliso, J.M. ${ }^{a}$, Los Navieros Vascos y la Marina Mercante en España, 18601935. Una historia económica, Instituto Vasco de Administración Pública, Bilbao, 1991.

Williams, T., A History of British Gas Industry, Oxford University Press, London, 1981.

WiLLIOT, J.-P., «La reconstruction de l'industrie gazière après la Première Guerre mondiale: une rationalisation économique appuyée sur de nouveaux choix techniques», en BussiÈre, E., Marcilloux, P. y VaraschiBn, D., La Grande Reconstruction. Reconstruire le Pas-de-Calais après la Gran Guerre, Actes du colloque d'Arras, Archives Départementales du Pas-de-Calais, Arras, 2002. 


\section{Financiación}

Este trabajo forma parte de los resultados del Proyecto I + D «La Industria del Gas en España: desarrollo y trayectorias regionales (18422008)», HAR2017-82112, financiado por el Ministerio de Economía, Industria y Competitividad del Gobierno de España y el Fondo Europeo de Desarrollo Regional (FEDER). Ha sido posible gracias a la estancia de investigación realizada en 2015 en The Cañada Blanch Centre for Contemporary Spanish Studies, The London School of Economics and Political Science, agradezco especialmente el apoyo recibido por el profesor Paul Preston, su director, y a Susana Grau, Office Manager. También deseo agradecer a Juan Manuel Matés Barco, Martín Rodrigo de Alharilla y los evaluadores anónimos sus sugerencias que han contribuido a mejorar el texto.

\section{Datos de la autora}

Licenciada en Historia y Doctora en Historia por la Universidad de Málaga. Profesora Titular de Historia Contemporánea de la Universidad de Málaga. Especialista en historia urbana, historia de los servicios públicos, historia industrial, historia empresarial e historia del gas y la electricidad. Investigadora principal del Proyecto I +D de Excelencia «La Industria del Gas en España: desarrollo y trayectorias regionales (1842-2008), HAR2017-82112-P. 